\title{
Crystallization Properties of the Glass Ceramics Prepared from Iron-Rich Nickel Slag
}

\author{
Kongjin Zhou ${ }^{1,2}$, Qinglin Zhao ${ }^{1,2, *}$, Yulin Zhang ${ }^{3}$ \\ ${ }^{1}$ State Key Laboratory of Silicate Materials for Architecture, Wuhan University of Technology, China \\ ${ }^{2}$ School of Materials Science and Engineering, Wuhan University of Technology, China \\ ${ }^{3}$ China Shipbuilding Industry Equipment and Materials Wuhan Co., Ltd, China
}

Copyright $\subseteq 2017$ by authors, all rights reserved. Authors agree that this article remains permanently open access under the terms of the Creative Commons Attribution License 4.0 International License

\begin{abstract}
For the purpose of broadening the scope of applications of nickel slag, this paper focuses on the crystallization properties of glass ceramics with large amounts of iron-rich nickel slag. In this research, the properties including activation energy of crystallization, crystalline growth pattern, main crystalline phase and micro structure were discussed. It was shown that when $\mathrm{KNO}_{3}$ was added, the $\mathrm{Fe}^{2+}$ oxidized to $\mathrm{Fe}^{3+}$, the activation energy of crystallization increased from $283.70 \mathrm{~kJ} / \mathrm{mol}$ to 345.45 $\mathrm{kJ} / \mathrm{mol}$ and the Avrami changed from 2.40 to 2.35. The main crystalline phase for both samples was pyroxene and it grew in one-dimension.
\end{abstract}

Keywords Crystallization Properties, Glass Ceramics, Iron-Rich Nickel Slag, Pyroxene

\section{Introduction}

Nickel slag is an industrial waste during the melting of nickel laterite. it occupies large amounts of land and affects our environment due to its lacking of proper application. In view of present studies on nickel slag, the utilization and additional value were very low. The technology with which glass ceramics can be prepared from the industrial wastes is very important not only to solve the environment problems caused by the industrial wastes but also to sustain the development of the related industries. Therefore, it is promising to prepare the glass ceramics from the industrial wastes. The study on preparing the glass ceramics with the industrial wastes has been made since 1960s, and some results were widely reported [1]. And several systems can be used to prepare the glass ceramics, for example, the system of $\mathrm{SiO}_{2}-\mathrm{Al}_{2} \mathrm{O}_{3}-\mathrm{CaO}-\mathrm{MgO}, \mathrm{SiO}_{2}-\mathrm{Al}_{2} \mathrm{O}_{3}-\mathrm{CaO}-\mathrm{Fe}_{2} \mathrm{O}_{3}$, and $\mathrm{SiO}_{2}-\mathrm{Al}_{2} \mathrm{O}_{3}-\mathrm{CaO}-\mathrm{Na}_{2} \mathrm{O}$ [2-5]. In this research, how to prepare glass ceramics with high content iron-rich nickel slag (more than 90\%) was discussed. Considering the chemical composition of iron-rich nickel slag, this study was based on the $\mathrm{CaO}-\mathrm{MgO}-\mathrm{Al}_{2} \mathrm{O}_{3}-\mathrm{SiO}_{2}-\mathrm{Fe}_{2} \mathrm{O}_{3}(\mathrm{FeO})$ system. The bulk crystallization of the $\mathrm{CaO}-\mathrm{MgO}-\mathrm{Al}_{2} \mathrm{O}_{3}-\mathrm{SiO}_{2}$ system was difficult, therefore, $\mathrm{TiO}_{2}, \mathrm{ZrO}_{2}, \mathrm{Cr}_{2} \mathrm{O}_{3}$ or other nucleating agents should be added, which are usually very expensive. Alexander Karamanov found that $0.7 \mathrm{wt} \% \mathrm{Cr}_{2} \mathrm{O}_{3}$ could promote the nucleation and crystallization of the iron rich glass [6]. In this experiment, the nickel slag has a certain content of $\mathrm{Fe}_{2} \mathrm{O}_{3}$ and $\mathrm{Cr}_{2} \mathrm{O}_{3}$ which could act as nucleating agent. As a result, glass ceramics with iron-rich nickel slag is expected to lower the preparation cost.

\section{Experimental}

The nickel slag used in this study was an industrial waste obtained during the melting of nickel laterite. The chemical composition of the nickel slag (NS) was given in Tab. 1 and it shows that the iron content was $9.25 \mathrm{wt} \%$, while the $\mathrm{Cr}_{2} \mathrm{O}_{3}$ content was $0.70 \mathrm{wt} \%$, both of these were beneficial for the glass crystallization. $\mathrm{Sb}_{2} \mathrm{O}_{3}$ was used as defoamer and $\mathrm{KNO}_{3}$ was used for oxidation; both of them were chemical pure. Tab. 2 presents the formulation of each glass ceramic, among them, the parent glass without $\mathrm{KNO}_{3}$ labeled NK and another with $\mathrm{KNO}_{3}$ labeled $\mathrm{K}$. All the melting was carried out in an electrical furnace at $1500^{\circ} \mathrm{C}$ for 1.5 hours, the molten material was cast into a graphite mold and annealed at $650^{\circ} \mathrm{C}$ for $1 \mathrm{~h}$, then cooled to room temperature.

Table 1. Chemical composition of nickel slag (wt\%)

\begin{tabular}{|c|c|c|c|c|c|c|c|c|}
\hline Composition & $\mathrm{SiO}_{2}$ & $\mathrm{Al}_{2} \mathrm{O}_{3}$ & $\mathrm{Fe}_{2} \mathrm{O}_{3} \#$ & $\mathrm{CaO}$ & $\mathrm{Cr}_{2} \mathrm{O}_{3}$ & $\mathrm{MgO}$ & Others & Ignition loss \\
\hline Content & 51.00 & 5.27 & 9.25 & 11.89 & 0.70 & 19.95 & 1.69 & 0.25 \\
\hline
\end{tabular}

$\mathrm{Fe}_{2} \mathrm{O}_{3} \#$ represents the total amount of $\mathrm{FeO}+\mathrm{Fe}_{2} \mathrm{O}_{3}$, similarly hereinafter 
Table 2. Formulation of the iron-rich glass ceramics $(\mathrm{g})$

\begin{tabular}{|c|c|c|c|}
\hline Sample & Nickel Slag & $\mathrm{KNO}_{3}$ & $\mathrm{Sb}_{2} \mathrm{O}_{3}$ \\
\hline $\mathrm{K}$ & 100 & 2.34 & 8.44 \\
\hline $\mathrm{NK}$ & 100 & 0 & 8.44 \\
\hline
\end{tabular}

The samples were heated to $700,750,800$ and $880^{\circ} \mathrm{C}$ for $30 \mathrm{~min}$ respectively. The kinetics of the crystallization of iron-rich nickel slag glass ceramics was determined by DTA which was performed in a Netzch STA 449 thermoanalyser using $10.5 \pm 1 \mathrm{mg}$ powder samples with heating rates of 5, 10, 15 and $20^{\circ} \mathrm{C} / \mathrm{min}$ from ambient temperature to $1200^{\circ} \mathrm{C}$. All the experiments were performed in an air atmosphere with $\mathrm{A}_{2} \mathrm{O}_{3}$ powder as reference material. The crystalline phases of these glasses were detected by XRD (D8-Advance, Bruker). The $\mathrm{Cu} \mathrm{k}_{\alpha}$ radiation $(\lambda=0.15405 \mu \mathrm{m})$ was used at 40 $\mathrm{kV}$ and $40 \mathrm{~mA}$. X-ray patterns were gathered in the range $10-70^{\circ} 2 \theta$ with a step size of $0.02^{\circ}$ and a step time of $5 \mathrm{~s}$. The fractured surface of the glass ceramics was etched in $4 \% \mathrm{HF}$ solution for $30 \mathrm{~s}$ at room temperature for FESEM (Ultra plus-43-13, Zeiss) observation.

\section{Results and Discussion}

\subsection{Activation Energy and Growth Pattern}

The DTA curves of the glass ceramics are presented in Fig. 1. It shows the glass transition temperature, $\mathrm{Tg}$ and crystalline peak temperature, $\mathrm{Tp}$.

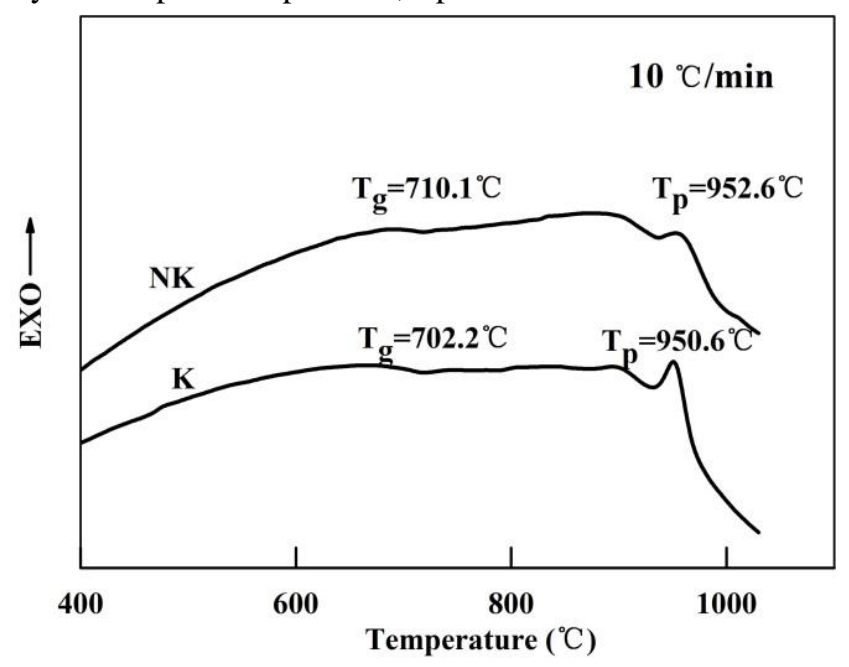

Figure 1. DTA curves of $K$ and NK sample
Fig. 1 shows that crystalline peak temperatures for the $\mathrm{K}$ sample and the NK sample are almost the same, but the exothermic peak of $\mathrm{K}$ sample was more pointed, which indicates that the $\mathrm{K}$ sample crystallized faster and the degree of crystallization was higher. At the same time, the Tg of the two samples are similar, illustrating their nucleating temperatures would be close. As we all know, the effective nucleating temperature was between $\mathrm{Tg}$ and $\mathrm{Tg}+50^{\circ} \mathrm{C}$, in this study, the $\mathrm{K}$ and $\mathrm{NK}$ samples were heat treated to 700,750 and $800^{\circ} \mathrm{C}$ for $30 \mathrm{~min}$ for nucleation [7].

The activation energy of crystal growth, $\mathrm{E}_{\mathrm{c}}$, could be estimated by using the Ozawa equation, shown as equation 1 , based on DTA experiments at different heating rates $[8,9]$ :

$$
\ln \beta=-\frac{1.052 \mathrm{E}_{\mathrm{C}}}{\mathrm{R} \mathrm{T}_{\mathrm{P}}}+\mathrm{C}
$$

Where $T_{p}$ is the crystalline peak temperature of the DTA trace, $\beta$ is the heating rate, $\mathrm{R}$ is the gas constant and $\mathrm{C}$ is a constant number. A plot of $\ln \beta \mathrm{Vs} 1 / \mathrm{Tp}$ is a straight line, whose slope corresponds to $E_{c}$. The value of $n$ could also be evaluated by a single DTA experiment using the Augis and Bennett equation shown as equation 2 [10].

$$
\mathrm{n}=\frac{2.5}{\Delta \mathrm{T}} \times \frac{\mathrm{RT}_{\mathrm{P}}^{2}}{\mathrm{Ec}}
$$

Where $\mathrm{n}$ is the Avrami constant, $\Delta \mathrm{T}$ is the width of the crystallization peak at half height, $T_{p}$ is the crystallization peak temperature of the DTA trace, $\mathrm{R}$ is the gas constant and $\mathrm{E}_{\mathrm{c}}$ is the activation energy of crystal growth.

The crystallization peak temperature $\left(\mathrm{T}_{\mathrm{p}}\right)$ of $\mathrm{K}$ sample and NK sample are shown in Tab. 3 and the activation energy of crystal growth $\left(\mathrm{E}_{\mathrm{c}}\right)$ is shown in Fig. 2.

Table 3. Crystallization peak temperature $\left(T_{P}\right)$ of $K$ sample and $N K$ sample from DTA curves

\begin{tabular}{|c|c|c|c|c|}
\hline \multirow{2}{*}{ Sample } & \multicolumn{4}{|c|}{ Heating rate $\left(\mathrm{K} \cdot \mathrm{min}^{-1}\right)$} \\
\cline { 2 - 5 } & 5 & 10 & 15 & 20 \\
\hline K & 1199.85 & 1223.75 & 1238.45 & 1246.65 \\
\hline NK & 1200.05 & 1225.75 & 1246.75 & 1257.05 \\
\hline
\end{tabular}



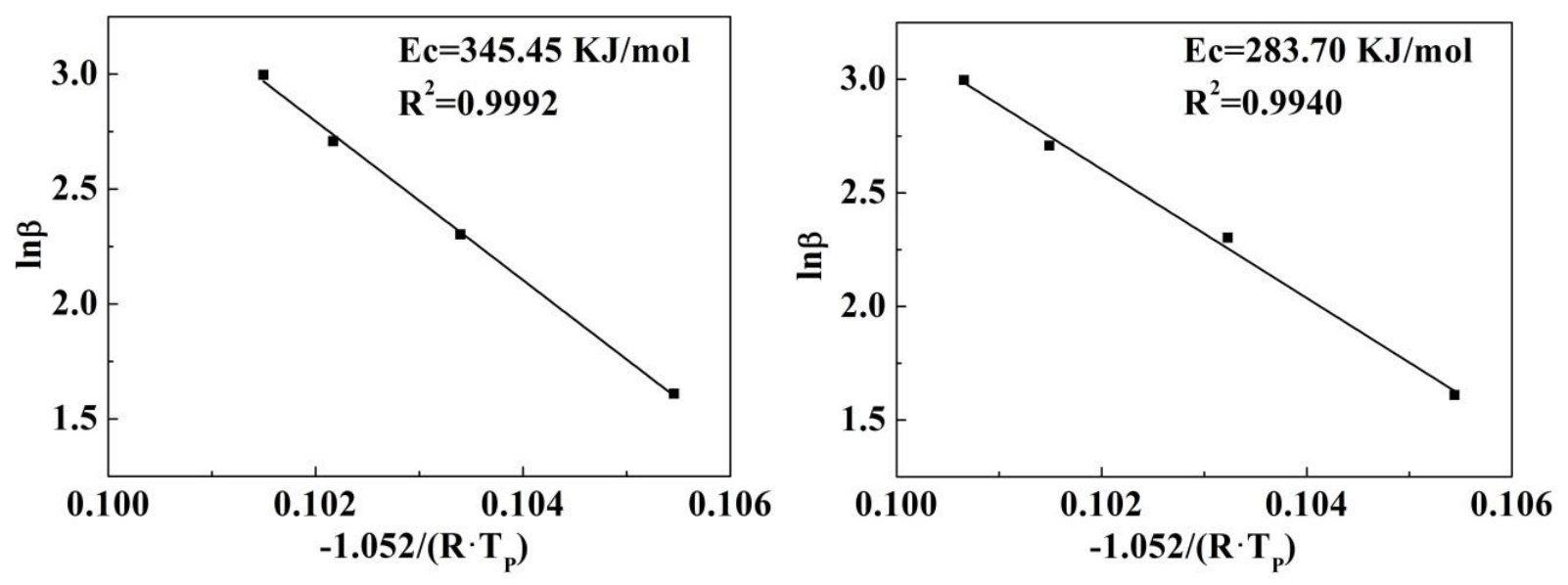

Figure 2. Activation energy of crystal growth for K (left) and NK sample (right)

Judging from Fig. 2, activation energy of crystal growth for $\mathrm{K}$ sample was $345.45 \mathrm{KJ} / \mathrm{mol}$ and NK sample was $283.70 \mathrm{KJ} / \mathrm{mol}$, so NK sample crystallized easier than K sample. This was owing to the original sample of the nickel slag being formed in a reducing atmosphere, therefore, the iron ions existed as $\mathrm{Fe}^{2+}$; when enough oxidizing agent $\mathrm{KNO}_{3}$ was added, they were oxidized to $\mathrm{Fe}^{3+}$. It is known that in the $\mathrm{CaO}-\mathrm{MgO}-\mathrm{Al}_{2} \mathrm{O}_{3}-\mathrm{SiO}_{2}-\mathrm{Fe}_{2} \mathrm{O}_{3}(\mathrm{FeO})$ system, $\mathrm{Fe}^{2+}$ destroys the $\mathrm{Si}-\mathrm{O}$ net structure which leads to a decrease in the viscosity of glass. However, $\mathrm{Fe}^{3+}$ could form $\left[\mathrm{FeO}_{4}\right]$ or $\left[\mathrm{FeO}_{6}\right]$, with $\mathrm{CaO}$ and $\mathrm{MgO}$ forming a net structure and thereby increasing the viscosity [11-15]. Based on this theory, $\mathrm{K}$ sample is expected to enhance the control of glass crystallization because the iron exists as $\mathrm{Fe}^{3+}$ which tends to increase the viscosity. $\mathrm{Fe}^{3+}$ could hinder the $\mathrm{Ca}_{2}+$ and $\mathrm{Mg}_{2}+$ fusion, go against the adjustment of the net structure, and therefore, increase the activation energy and avoid glass crystallization during cooling.

Different Avrami parameters (n) corresponded to different crystal growth pattern. The higher the value of $n$, the more crystal dimensions exist, as shown in Tab. 4. Tab. 5 shows the $n$ value of $\mathrm{K}$ sample and NK samples at different heating rates calculated by the Augis and Bennett equation.

Table 4. Avrami parameters (n) for different crystallization mechanism [16]

\begin{tabular}{|c|c|}
\hline Mechanism-bulk nucleation & Avrami parameters (n) \\
\hline Surface crystallization & 1 \\
\hline One-dimensional crystal growth & 2 \\
\hline Two-dimensional crystal growth & 3 \\
\hline Three-dimensional crystal growth & 4 \\
\hline
\end{tabular}

Table 5. Avrami parameters for K sample and NK sample

\begin{tabular}{|c|c|c|c|c|c|}
\hline Sample & 5 & 10 & 15 & 20 & Average \\
\hline $\mathrm{K}$ & 2.26 & 2.38 & 2.45 & 2.32 & 2.35 \\
\hline $\mathrm{NK}$ & 2.35 & 2.46 & 2.42 & 2.38 & 2.40 \\
\hline
\end{tabular}

It was seen from Tab. 5 that the average Avrami parameters for K sample and NK sample were 2.35 and 2.40, respectively, and the different heating rates had little influence on the Avrami parameters. From Tab. 5, it can be seen that the crystal grew in a one dimensional chain both for $\mathrm{K}$ sample and NK sample, indicating the iron valence state had little effect on the crystal growth pattern, which could be verified by FESEM.

\subsection{Crystalline Phase}

In order to investigate the different crystallization of nickel slag glass ceramics at different heating temperatures, XRD tests were carried out at $700^{\circ} \mathrm{C}, 750^{\circ} \mathrm{C}, 800^{\circ} \mathrm{C}$ and $880^{\circ} \mathrm{C}$ for 30 min, the results were shown as Fig. 3 .

From Fig. 3 (left) showed that there was little difference between $\mathrm{K}$ sample and NK sample during nucleation process and an obvious broad amorphous peak between $20^{\circ}$ and $40^{\circ}$ at all the nucleating temperatures at 700,750 and $800^{\circ} \mathrm{C}$ for both $\mathrm{K}$ and NK sample, indicating few crystals were formed in nickel slag glass ceramics. As for Fig. 3 (right), when the heating temperature was at $880^{\circ} \mathrm{C}$, an obvious crystal peak could be observed, suggesting a crystal precipitation of nickel slag with main crystalline phase being pyroxene, known as $\mathrm{Ca}(\mathrm{Mg}, \mathrm{Fe})(\mathrm{Si}, \mathrm{Al})_{2} \mathrm{O}_{6}$ both for $\mathrm{K}$ and $\mathrm{NK}$ samples. Because the composition of the original glass was complicated, the crystalline structure formed was a solid solution-pyroxene. A small but broad amorphous peak existed, showing a perfect crystallization precipitation and indicating different valence state of $\mathrm{Fe}$ had little influence on the main crystalline phase [17]. Though the peak positions were almost the same between $\mathrm{K}$ and NK sample, the peak intensity of K sample was much higher than NK sample, and compared with Fig. 1, the peak of K sample in DTA curve was also more pointed than for NK sample, both of these could illustrate that $\mathrm{Fe}^{3+}$ could promote crystalline growth, although the iron ion valence state did nothing to the main crystalline phase. Because the activation energy of NK sample was lower than $\mathrm{K}$ sample, the phase separation was more obvious and nucleation positions were huge; all of these would lead to easier crystallization. However, with the crystalline structure growing, the glass phase decreased, the crystalline structure competed with each other, excess crystal 
nuclei hindered the growth of crystalline structures and the crystallization was worse than that for K sample [18]. All of these results confirmed that the $\mathrm{KNO}_{3}$ could improve the glass ceramics properties.

\subsection{Micro Structure}

For the purpose of clearly observing $\mathrm{K}$ and NK samples' growth, $\mathrm{K}$ and $\mathrm{NK}$ samples were kept at 700,750 and $800^{\circ} \mathrm{C}$ for $30 \mathrm{~min}$ and then immersed in $4 \% \mathrm{HF}$ for $30 \mathrm{~s}$. After that, the samples were tested by FESEM for morphology structure. The results were shown at Fig. 4.

From Fig. 4, at the same heating temperature, NK sample phase separation was more obvious than $\mathrm{K}$ sample, confirming the lower activation energy once again and coinciding with the previous result calculated by equation 2 . At the same time, for $\mathrm{K}$ sample, obvious phase separation existed for all the heating temperature. However, based on the XRD results, there was no crystalline structure, so all the precipitation in $\mathrm{K}$ sample was liquid droplets. For NK

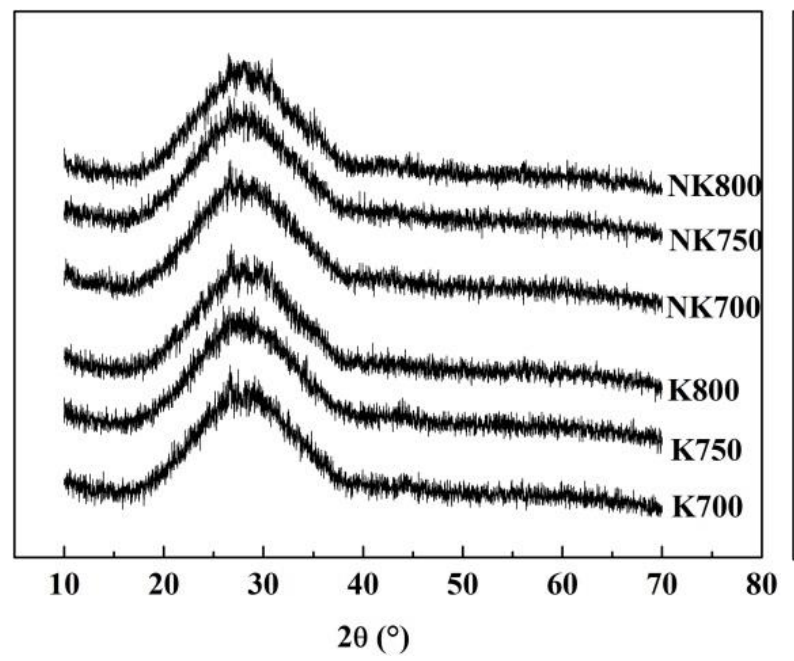

sample, when heated to $700^{\circ} \mathrm{C}$, a lot of spherical liquid existed with diameter about $20 \mathrm{~nm}$, amongst which, a certain quantity of droplets began vertical growth and formed needle like structures. When heated to $750^{\circ} \mathrm{C}$, the needles disappeared and the droplets' diameter increased to $40 \mathrm{~nm}$; when the temperature increased to $800^{\circ} \mathrm{C}$, the droplets' sizes changed little, but were connected with each other even in aggregation. Based on the previous study, the spherical droplets perhaps were an iron-rich phase while the other was a silicate-rich phase; at the interface, it was much easier to undergo heterogeneous nucleation, provided numerous nucleation positions existed which made it much easier for crystallization to occur $[19,20]$. The higher the nucleating temperature gets, the more obvious the difference of phase separation for $\mathrm{K}$ and NK samples is. When heated to $800^{\circ} \mathrm{C}$, NK sample droplets began to aggregate, while K sample did nothing, indicating $\mathrm{Fe}^{2+}$ could promote to phase separation, made crystallization easier, and thus affect the original glass in cooling process.

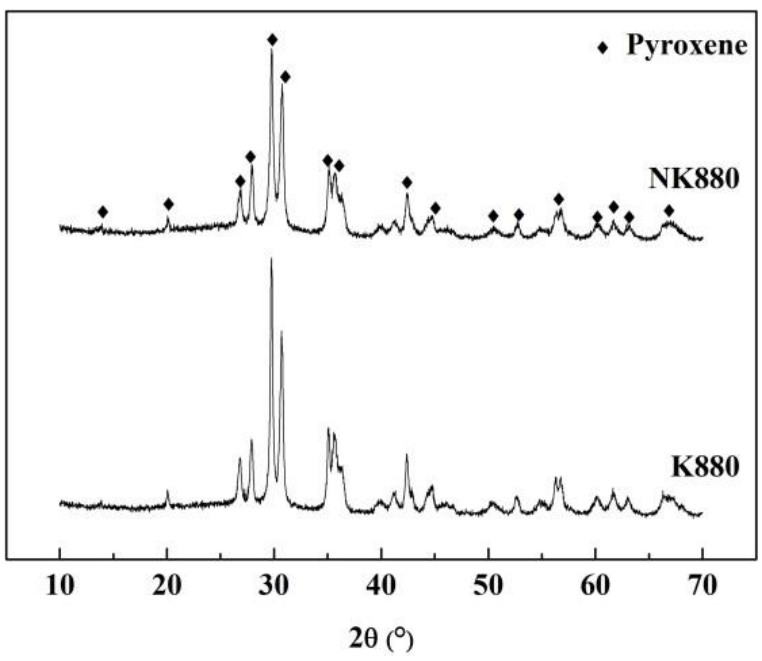

Figure 3. Heat treated at $700,750,800^{\circ} \mathrm{C}$ (left) and $880^{\circ} \mathrm{C}$ (right) for $30 \mathrm{~min}$
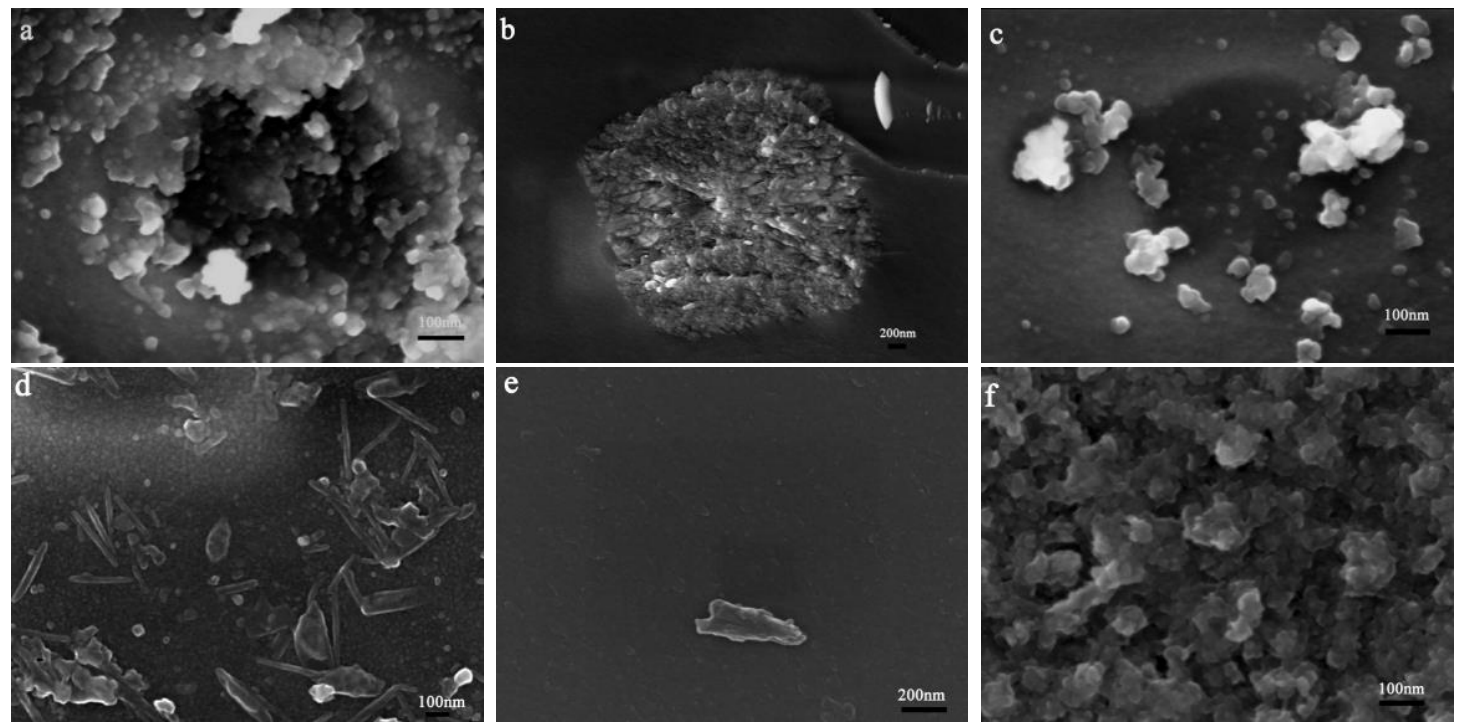

Figure 4. FESEM of different sample: a) $\mathrm{K}$ sample at $700^{\circ} \mathrm{C}$ for $30 \mathrm{~min}$; b) $\mathrm{K}$ sample $750^{\circ} \mathrm{C}$ for $30 \mathrm{~min}$; c) $\mathrm{K}$ sample $800^{\circ} \mathrm{C}$ for $30 \mathrm{~min}$; d) $\mathrm{NK}$ sample at $700^{\circ} \mathrm{C}$ for $30 \mathrm{~min}$; e) $\mathrm{NK}$ sample at $750^{\circ} \mathrm{C}$ for $30 \mathrm{~min}$; f) NK sample at $800^{\circ} \mathrm{C}$ for $30 \mathrm{~min}$ 

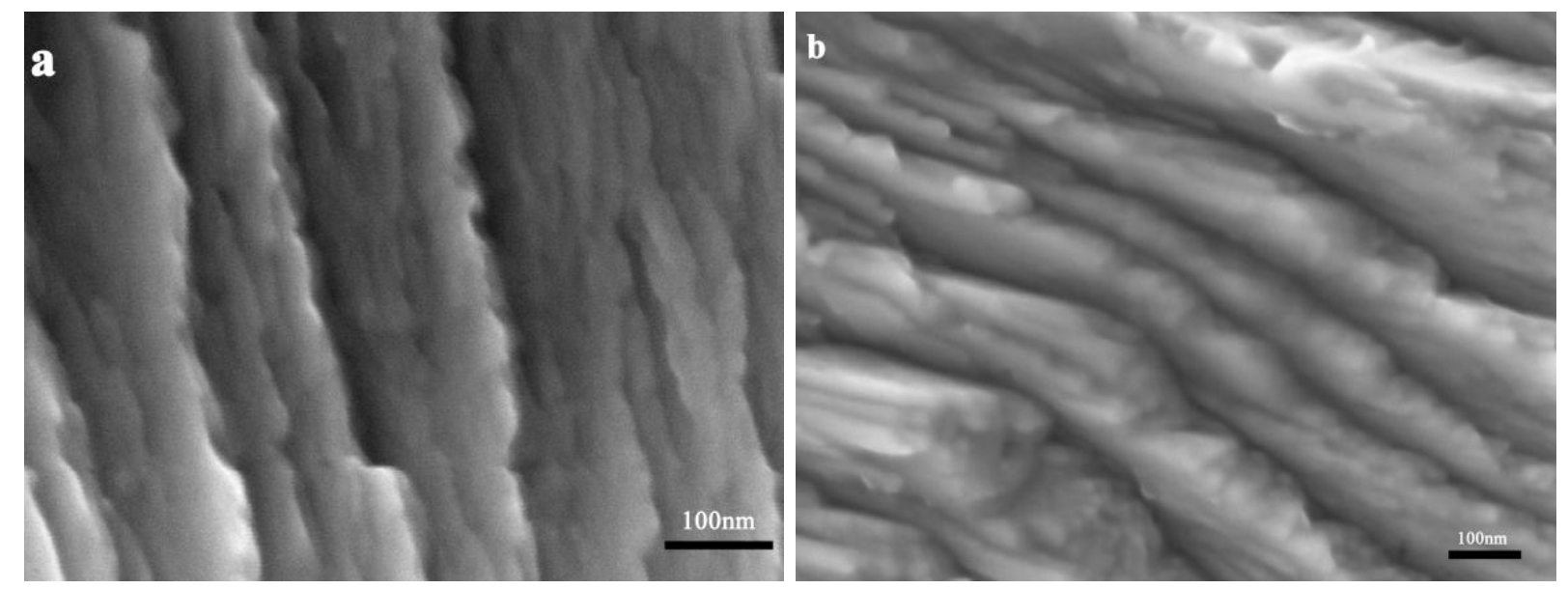

Figure 5. FESEM of the glass ceramics: a) $\mathrm{K}$ sample at $880^{\circ} \mathrm{C}$ for $30 \mathrm{~min}$; b) NK sample at $880^{\circ} \mathrm{C}$ for $30 \mathrm{~min}$

In order to confirm the crystalline growth in crystallization, $\mathrm{K}$ and NK samples were heated to $880^{\circ} \mathrm{C}$ for 30 min, then observed the FESEM, shown as Fig. 5.

It could be seen from Fig. 5 that $\mathrm{K}$ and NK samples grew in one dimensional chain. From the result of XRD in section 3.1 , the main crystalline phase was pyroxene growing in a chain, which corresponded with the FESEM result. What's more, taking the Avrami constant discussed in section 3.1 into consideration, which was calculated to be 2.40 and 2.35 respectively, a one-dimensional growth style is confirmed, corresponding with the FESEM result. That is, all the tests showed the same result: that the crystalline main phase was pyroxene and confirmed it to be a reliable result. Besides, the crystals' horizonal size for NK sample was about $100 \mathrm{~nm}$ while being $120 \mathrm{~nm}$ for $\mathrm{K}$ sample, so there were more crystals in NK sample. However, numerous crystals led to more interaction with each other and worsened the mechanical properties because of competing growth. Both the samples grew in the $\mathrm{c}$ axis and were arranged densely in a horizontal direction, so there were good mechanical properties in nickel slag glass ceramics [21].

\section{Conclusions}

It was feasible to prepare glass ceramics with a high content of iron-rich nickel slag without any crystallization agent, the main crystalline phase being pyroxene. When $\mathrm{KNO}_{3}$ was added, the activation energy increased from $283.70 \mathrm{~kJ} / \mathrm{mol}$ to $345.45 \mathrm{~kJ} / \mathrm{mol}$, the Avrami constant changed from 2.40 to 2.35, while still growing in a one dimensional chain pattern; $\mathrm{Fe}^{2+}$ was oxidized to $\mathrm{Fe}^{3+}$ in $\mathrm{KNO}_{3}$ ambient, increasing the activation energy of crystallization, avoiding to rapid crystallization, enhancing the control of crystallization, thus benefiting crystalline growth, and increasing the crystalline phase content.

\section{Abbreviations}

XRD X-ray diffraction

DTA differential thermal analysis
FESEM field emission scanning electron microscope

\section{Acknowledgements}

The authors are grateful to the National Natural Science Foundation of China for supporting the research reported in this paper, under grant number 51202173.

\section{REFERENCES}

[1] P. Colombo, G. Brusatin, E. Bernardo, et al.. Inertization and reuse of waste materials by verification and fabrication of glass-based products. Curr. Opin. Solid State Mater. Sci.,7(2003), No.3, p.225

[2] A. Karamanov, P. Pisciella, and M. Pelino. The crystallisation kinetics of iron rich glass in different atmospheres. J. Eur. Ceram. Soc., 20(2000), No.12, p.2233

[3] A. Karamanov and M. Pelino. Crystallization phenomena in iron-rich glasses. J. Non Cryst. Solids, 281(2001), No.1-3, p.139

[4] P. Pisciella and M. Pelino. Thermal expansion investigation of iron rich glass-ceramic. J. Eur. Ceram. Soc., 28(2008), No.16, p.3021

[5] P.M. Sørensen, M. Pind, Y.Z. Yue, et al.. Effect of the redox state and concentration of iron on the crystallization behavior of iron-rich aluminosilicate glasses. J. Non Cryst. Solids, 351(2005), No.14-15, p.1246

[6] Karamanov, A., Pisciella, P., Pelino, M.: The effect of Cr2O3 as a nucleating agent in iron-rich glass-ceramics. J. Eur. Ceram. Soc. 19, 2641-2645(1999)

[7] Eegul, S., Ferrante, F., Pisciella, P., et al.: Characterization of basaltic tuffs and their applications for the production of ceramics and glass-ceramic materials. Ceram. Int. 35, 2789-2795(2009)

[8] Păcurariu, C., Lazău, R. I., Lazău, I., et al.: Non-isothermal crystallization kinetics of some basaltic glass-ceramics 
containing $\mathrm{CaF}_{2}$ as nucleation agent. J. Therm. Anal. Calorim. 97, 507-513(2009)

[9] Păcurariu,C., Lită, M., Lazău, I., et al.: Kinetic study of the crystallization process of some glass ceramics based on basalt, via thermal analysis. J. Therm. Anal. Calorim. 72, $811-821(2003)$

[10] Francis, A. A.: Crystallization kinetics of magnetic glass-ceramics prepared by the processing of waste materials. Mater. Res. Bull. 41, 1146-1154(2006)

[11] Wang, Z. J., Ni, W., Li, K. Q., et al.: Crystallization characteristics of iron-rich glass ceramics prepared from nickel slag and blast furnace slag. Int. Miner. 18, 455-459(2011)

[12] Rüssel, C., Wiedenroth, A.: The effect of glass composition on the thermodynamics of the $\mathrm{Fe}^{2+} / \mathrm{Fe}^{3+}$ equilibrium and the iron diffusivity in $\mathrm{Na}_{2} \mathrm{O} / \mathrm{MgO} / \mathrm{CaO} / \mathrm{Al}_{2} \mathrm{O}_{3} / \mathrm{SiO}_{2}$ melts. Chem. Geol. $213,125-135(2004)$

[13] Romero, M., Rincón, J. M., Acosta, A.: Effect of iron oxide content on the crystallization of a diopside glass-ceramic glaze. J. Eur. Ceram. Soc. 22, 883-890(2002)

[14] Burkhard, D. J. M., Scherer, T.: The effect of initial oxidation state on crystallization of basaltic glass. J. Non-Cryst. Solids. $352,3961-3969(2006)$
[15] Métrich, N., Susini, J., Foy, E., et al.: Redox state of iron in peralkaline rhyolitic glass/melt: X-ray absorption microspectroscopy experiments at high temperature. Chem. Geol. $231,350-363(2006)$

[16] Bayrak, G., Yilmaz, S.: Crystallization kinetics of plasma sprayed basalt coatings. Ceram. Int. 32, 417-481(2006)

[17] Karamanov, A., Pisciella, P., Pelino, M.: The crystallization kinetics of iron rich glass in different atmospheres. J. Eur. Ceram. Soc. 20, 2233-2237(2000)

[18] Karamanov, A., Eegul, S., Akyildiz, M., et al.: Sinter-crystallization of a glass obtained from basaltic tuffs. J. Non-Cryst. Solids. 354, 290-295(2008)

[19] Wang, Z. J., Ni, W., Jia, Y., et al.: Crystallization behavior of glass ceramics prepared from the mixture of nickel slag, blast furnace slag and quartz sand. J. Non-Cryst. Solids. 356, 1554-1558(2010)

[20] Romero, M., Rincbn, J. M.: Preparation and Properties of High Iron Oxide Content Glasses Obtained from Industrial Wastes. J. Eur. Ceram. Soc. 18, 153-160(1998)

[21] Cocić, M., Logar, M., Matovic, B., et al.: Glass-ceramics obtained by the crystallization of basalt. Sci. Sinter. 42, 383-388(2010) 